\title{
A dimensão meritocrática dos testes estandardizados e a responsabilização unilateral dos docentes
}

\author{
The dimension of meritocratic standardized tests and accountability unilateral \\ of teachers \\ La dimensión meritocrática de las evaluaciones externas y la \\ responsabilización unilateral de los docentes
}

LEONICE MATILDE RICHTER VILMA APARECIDA SOUZA

MARIA VIEIRA SILVA

Resumo: Analisa-se a relação entre as políticas educacionais elaboradas pelo Estado e a intensificação do trabalho docente mediante testes estandardizados na educação brasileira, a qual é entendida como estratégia inerente à sua lógica gerencial. Como recorte empírico realizamos questionários e entrevistas com profissionais da rede Estadual de ensino de Minas Gerais. Os resultados evidenciam a responsabilização unilateral docente pelos resultados dos testes; omissão do Estado na promoção de condições de trabalho e a promoção de princípios competitivos e meritocráticos na escola pública.

Palavras-chave: Avaliação externa; estado avaliador; políticas educativas; trabalho docente.

\begin{abstract}
This paper analyzes the relationship between the educational policies developed by the state and the intensification of teaching through standardized tests in Brazilian education, understood as a strategy inherent in its management logic. As empirical clipping, we conducted questionnaires and interviews with professionals from the State network of Minas Gerais education. The results show the teaching unilateral accountability for the results of tests, the State's failure to promote working conditions, and the promoting of principles and adherence to competitive and meritocratic logic in the public school.
\end{abstract}

Keywords: External assessment; state of evaluation; educational policies; teaching work.

Resumen: Se analiza la relación entre las políticas educacionales elaboradas por el Estado y la intensificación del trabajo docente frente a evaluaciones estandarizadas en la educación brasileña, que se entiende como una estrategia inherente a su lógica de gestión. Como recorte empírico realizamos cuestionarios y entrevistas con profesionales de la red estatal de enseñanza de Minas Gerais. Los resultados muestran la responsabilización unilateral docente por los resultados de las evaluaciones; omisión del Estado para promover condiciones de trabajo y la promoción de los principios competitivos y meritocráticos en la escuela pública.

Palabras clave: Evaluación externa; estado evaluador; políticas educativas; trabajo docente. 


\section{INTRODUÇÃO}

Nas últimas três décadas, presenciamos no Brasil, no âmbito das políticas públicas de educação, o expressivo protagonismo da avaliação em larga escala. Esse fenômeno não é peculiar apenas ao contexto brasileiro; ao contrário, faz parte de uma agenda neoliberal globalmente estruturada (DALE, 2004), ainda que a materialidade dos diferentes países, com suas idiossincrasias, guarde aspectos particulares das disputas políticas e econômicas, tanto no interior dos países quanto na relação e na posição destes na dinâmica internacional. Nesse sentido, tendo como aporte as mudanças ocorridas na configuração do Estado prestador de serviço para o Estado avaliador, propomo-nos a analisar a avaliação em larga escala como estratégia importante nessas mutações, assim como seus impactos na organização escolar, via de regra estruturada por princípios meritocráticos e competitivos, correlatos de uma nova relação "público-privado".

Parte-se do pressuposto de que o Estado contemporâneo se constitui numa instituição chave de intervenção para a manutenção da produtividade do sistema capitalista e que as crises estruturais do capital interferem diretamente em todas as instituições do Estado e em suas formas de governo, sendo a avaliação uma dessas formas estratégicas de sua configuração atual.

Para tanto, ao longo do artigo, três aspectos são trabalhados. Primeiro, o debate acerca da reprodução sociometabólica do capitale, segundo, a reconfiguração do Estado. Para análise dos efeitos dos novos processos de avaliação com base no campo empírico, exploramos, num terceiro momento, a perspectiva dos professores da rede Estadual de Educação de Uberlândia-MG acerca da relação entre avaliação em larga escala e as condições do trabalho docente efetivadas pelo Estado. Ater-nos-emos à síntese de uma pesquisa realizada em 29 escolas entre os anos 2012 e 2014.

As escolas foram selecionadas a partir dos seguintes critérios: das 69 escolas estaduais da jurisdição do município naquele ano, elegemos as que ofereciam tanto anos iniciais quanto finais do Ensino Fundamental, vista a intenção de realizar entrevistas tanto com os professores do quinto quanto do nono ano desse nível de ensino. Também, restringimos apenas às escolas que apresentam resultados de Ideb (índice de Desenvolvimento da Educação Básica) nos anos iniciais e finais nos anos de 2005; 2007 e 2009. O objetivo não era explorar baixo e alto Ideb, mas sim a flutuação do índice, seja de elevação, redução ou estagnação, uma vez que considerávamos que essas características geram impactos distintos sobre o trabalho dos docentes que atuam nessas diferentes escolas. Foi também este o motivo que nos levou a não restringir as escolas que fossem eleitas a partir 
destes critérios. Assim, compomos uma amostra de 30 instituições que atendiam às características supracitadas, das quais uma não aceitou participar.

Realizamos questionários e entrevistas semiestruturadas com 225 sujeitos, sendo 83 professores do nono ano do Ensino Fundamental (em cada escola participaram um professor de Português, um de Matemática e um professor de outra disciplina); 58 professores do quinto ano do Ensino Fundamental; 55 Especialistas da Educação Básica (EEB) e 29 diretores. As entrevistas foram realizadas essencialmente nas respectivas escolas dos participantes da pesquisa, com duração média de quarenta e cinco minutos. Explorou-se o levantamento do perfil sociodemográfico dos professores e três blocos de questões semiestruturadas, um sobre as condições de trabalho do professor; outro, sobre a avaliação em larga escala na visão dos professores e questões específicas sobre as implicações do Ideb no trabalho docente.

\section{REPRODUÇÃO SOCIOMETABÓLICA DO CAPITAL E A RECONFIGURAÇÃO DO ESTADO}

A autorreprodução do capital tem como característica sua capacidade de administrar as crises e se recriar diante do possível colapso, considerando a contradição insuperável que faz parte da estrutura do sistema do capital. Ao longo do último século, o capital invadiu diferentes partes do planeta, indo além de fronteiras, conduzido por uma lógica global expansionista. Como efeito colateral, observam-se seus desdobramentos destrutivos, que, ao contrário da "modernização" anunciada, após décadas de "intervenção trombeteada em alto e bom som, só ofereceu a intensificação da pobreza, a dívida crônica, a inflação insolúvel e uma incapacitante dependência estrutural” (MÉSZÁROS, 2011, p. 92). E como parte dessa bem sucedida autorreprodução do capital, o slogan não há alternativa aos imperativos da ordem vigente foi inculcado ideologicamente para excluir qualquer questionamento e enfrentamento das rédeas capitalistas, que deixaram esse legado desanimador.

Contudo, o capital não pode ser compreendido como uma condição inalterável, mas, ao contrário, precisa ser entendido como um movimento dinâmico que, apesar de suas estratégias de autorreprodução e administração das crises, está suscetível à superação e precisa ser compreendido como um sistema de transição. Nessa lógica, Mészáros (2011) salienta que o capital não pode ser entendido como uma "entidade material" e um mecanismo neutro de mercado, como querem fazer crer seus apologistas, pois se trata de "uma poderosa - na verdade, até o presente, de longe a mais poderosa - estrutura totalizadora de controle à qual tudo o mais, inclusive seres humanos, deve se ajustar, e assim provar sua 'viabilidade 
produtiva"” (MÉSZÁROS, 2011, p. 96). Um sistema que subjuga todas as esferas (saúde, comércio, educação, agricultura e a arte) à sua lógica e a seus critérios de viabilidade, adentrando “desde as menores unidades de seu 'microcosmo' até as mais gigantescas empresas transnacionais, desde as mais íntimas relações pessoais aos mais complexos processos de tomada de decisão" (ibidem).

Assim, para manter-se como "estrutura totalizadora de controle", o capitalismo tem sido regido por um conjunto de estratégias e mecanismos de autorregulação que assumem características específicas de acordo com cada momento histórico, uma capacidade de autoconstituição que, na ausência de alternativa de superação, fortalece-se e aperfeiçoa seu modo de reprodução sociometabólica no processo de administração de suas crises. O que está em jogo é o movimento de autoconstituição circular do capital e sua capacidade de autorreprodução ampliada, o que pode ser observado acompanhando-se os últimos episódios de reestruturação produtiva e ajuste global. Com se observa, na década 1970, com a crise do padrão monetário internacional e os choques do petróleo, ao lado da reorganização das relações entre o centro hegemônico do capitalismo e os demais países do mundo capitalista, que deram início a um novo movimento de ajuste global. Paralelamente, assiste-se, também, a uma derrota política do chamado socialismo real, que desemboca numa generalização das políticas neoliberais.

Segundo análises de Antunes (2002), após longo período de acumulação capitalista, durante o período do taylorismo e do fordismo, com o Estado de bem-estar social, o capitalismo, a partir dos anos 1970, adentrou em um momento de crise de acumulação. A denominada crise do fordismo e do Estado Provedor representava a crise estrutural do capitalismo (com a combinação de uma profunda recessão, baixas taxas de crescimento econômico e altas taxas de inflação), uma manifestação do sentido destrutivo de sua lógica. Essa crise estrutural, dentre um amplo leque de consequências, provocou o processo de reestruturação do capitalismo, com o objetivo de recuperar seu ciclo produtivo.

Tal reestruturação implantou-se como uma resposta capitalista superficial, numa dimensão "fenomênica", isto é, uma reestruturação sem abalar os pilares essenciais do modo de produção capitalista. Foi uma reestruturação do padrão produtivo na tentativa de repor os patamares de acumulação, por meio da utilização de novos e velhos mecanismos de acumulação. Em resposta à crise, um processo de reestruturação do capitalismo se implementou com vistas a resgatar o ciclo produtivo. Esse processo teve como traços efetivos o advento do neoliberalismo, a privatização do Estado, a desregulamentação dos direitos trabalhistas, a desmontagem do setor produtivo estatal, como parte de um amplo sistema de reorganização ideológica e política de dominação (ANTUNES, 2002). 
Com isso, tem-se a estruturação de um projeto neoliberal como saída da crise, a partir da retomada dos preceitos clássicos do liberalismo adaptados ao momento histórico em questão. Como efeitos desse projeto, tem-se o enxugamento da estrutura do Estado, numa combinação de redução de investimentos sociais com os processos de privatização. A lógica predominante passa a ser definida em favor do mercado, tendo como justificativa sua suposta eficiência para administrar e gerenciar momentos de crise. O processo de "neoliberalização", que trouxe como receituário a desregulamentação do mercado, o processo de centralização do capital, sob a forma financeira e imprimindo um cenário de "mundialização do capital", expressão que segundo Chesnais (1995) exprime um novo cenário de "liberdade quase total" do capital que permite seu desenvolvimento, pela adoção de políticas desreguladoras que favoreceram sua expansão sob a forma financeira. Nesse processo, o Estado Provedor passou a ser visto como um entrave à expansão transnacional do capital, na medida em que essa instituição pode determinar políticas restritivas e protecionistas ao mercado interno. Com isso, a defesa neoliberal de reconfiguração do papel do Estado com o propósito de "criar e preservar uma estrutura institucional apropriada a essas práticas [livres mercados e livre comércio]; o Estado tem de garantir [...] a qualidade e a integridade do dinheiro". Além disso, de acordo com a doutrina neoliberal, "se não existirem mercados (em áreas como a terra, a água, a instrução, o cuidado de saúde, a segurança social [...]), estes devem ser criados, se necessário, pela ação do Estado" (HARVEY, 2008, p. 12). Ou seja, o Estado precisa assegurar as estruturas legais para a garantia da propriedade privada e o funcionamento dos mercados.

Em relação ao processo de redefinição do papel do Estado, Boron (2001) ressalta que sua atuação na condução da economia, nos moldes do neoliberalismo, passa a ser intensa, a partir das privatizações, das liberações de mercados internos e em ajustes no sistema financeiro. De acordo com essa lógica, presencia-se um movimento de reconfiguração mediante mecanismos de publicização, privatização e terceirização, que modificam as fronteiras entre os setores públicos e privados, com a prerrogativa de reduzir os custos com o aparelho estatal e assegurar maior eficiência na gestão dos serviços públicos. Nesse contexto, o gerencialismo traz à tona novas relações entre o Estado e o mercado, modificando, consideravelmente, a forma de conceber e implementar as políticas públicas. No âmbito da educação, o modelo gerencial introduz diretrizes advindas da gerência empresarial e da gestão do setor privado na organização e na gestão da educação.

Como parte da reforma gerencial do Estado, no que diz respeito às políticas educacionais, também veio em cena um novo discurso hegemônico, que passou a disseminar "soluções empresariais" para problemas sociais e educacionais. Nesse contexto, as agências internacionais de financiamento tiveram atuação 
efetiva na difusão desse novo modelo de gestão, exercendo forte influência nas agendas governamentais dos países em desenvolvimento, tanto pela concessão de empréstimos como pela abrangência de sua atuação, passando a defender diretrizes neoliberais de ajuste estrutural. Nesse contexto, a avaliação aparece como uma das estratégias utilizadas para operacionalizar tais propostas, representando uma nova forma de governo que valida novos discursos e novas formas de relação entre escola, sociedade e Estado.

\section{O PROTAGONISMO DO ESTADO AVALIADOR NA RELAÇÃO COM A ESCOLA}

A incorporação da ideologia do mercado para a educação, a responsabilização da escola e dos professores pelos resultados em testes estandardizados, novas formas de exclusão dos alunos, a publicação de rankings e o estímulo à competição entre escolas marcam a reforma em curso no âmbito da educação regida pelos ideais neoliberais. Na análise de Ball (2012), as tecnologias de comparação, mensuração e responsabilização não são apenas formas de monitorar os resultados, mas também mecanismos que reconfiguram o significado de ensino e do ensinar. A responsabilização baseada na lógica da culpabilização docente e da escola corrompe e degrada o trabalho docente, posto que altera a forma como os professores pensam sobre o que fazem e como se relacionam com os colegas e com os alunos.

Valores estão em disputas e, nessa relação de força, o coletivo e a sociabilidade perdem espaço para a competição. Para Ball (2012), o que está em curso é o propósito de reformar os profissionais do setor público, dentre eles o professor, ou seja, mudar o que significa ser professor, processo que promove mudanças profundas nas práticas profissionais e nas subjetividades do docente. Nessa conjuntura, a "prática da sala de aula é cada vez mais "composta" de respostas às novas exigências externas. Os professores são considerados e caracterizados de novas maneiras; cada vez mais eles são considerados como técnicos pedagógicos” (BALL, 2012, p. 40).

A centralidade da avaliação nesse processo de implementação de novos princípios no espaço da escola pública por uma gestão de Estado voltada para o controle dos resultados lhe atribui uma função primordialmente avaliadora. Afonso (1998) defende que a expressão "Estado Avaliador" remonta à perspectiva que estava em curso inicialmente em países capitalistas centrais (como os EUA

\footnotetext{
1 A expressão "Estado Avaliador”, de acordo com Afonso (1998), foi inicialmente utilizada para chamar a atenção para as mudanças no ensino superior, por Neave (1988); todavia, para aquele autor, ela passou a ser usada diante de outros domínios das políticas públicas e educativas.
}

612 - RBPAE - v. 31, n. 3, p. 607 - 625 set./dez. 2015 
e a Inglaterra) e que se estendeu ao longo da década de 1980 para outras nações. Em sentido amplo, é uma perspectiva que denota um Estado que adotou o ethos competitivo, que, segundo o autor, está "decalcado no que tem vindo a ser designado por neodarwinismo social, passando a admitir a lógica do mercado, com a importação para o domínio público de modelos de gestão privada cuja ênfase é posta nos resultados ou produtos do sistema educativo" (AFONSO, 1998, p.74).

Redução de investimentos e mecanismos de controle e responsabilização mais sofisticados fazem parte desse processo. Para tanto, a avaliação é lançada como pré-requisito para que seja possível a implementação desses mecanismos, ou seja, a avaliação ao ser orientada por esses princípios, contribui para incorporar à esfera do Estado e da educação pública a lógica de mercado.

Para Afonso (1998), em termos de política educativa, trata-se de conciliar o Estado avaliador (preocupado com a imposição de um currículo nacional) e a filosofia de mercado educacional (interessado na diversificação da oferta e na competição entre escolas), e um dos vetores fundamentais nesse processo é a avaliação (cf. AFONSO, 1998). A avaliação que dá conta deste "paradoxo do Estado neoliberal" é designada pelo autor como avaliação estandardizada criterial com publicação de resultado.

\footnotetext{
Por um lado, o Estado quer controlar mais de perto os resultados escolares e educacionais (tornando-se assim mais Estado, Estado Avaliador), mas, por outro lado, tem que partilhar esse escrutínio com os pais e outros "clientes" ou "consumidores" (diluindo também por aí algumas fronteiras tradicionais, e tornando-se mais mercado e menos Estado). Produz-se assim um mecanismo de quase mercado em que o Estado, não abrindo mão da imposição de determinados conteúdos e objetivos educacionais (de que a criação de um currículo nacional e apenas um exemplo), permite, ao mesmo tempo, que os resultados/produtos do sistema educativo sejam também controlados pelo mercado (AFONSO, 1998, p.168-169).
}

Destaca-se, no entanto, que essas "dimensões se (con)fundiram em articulações muito específicas de país para país" (ibidem), o que demanda particularidades da avaliação para dar conta dessa realidade (aparentemente) contraditória. Em análises mais recentes, Afonso (2013) deu contornos ao que designa três fases do Estado-avaliador (fases que coexistem ou podem coexistir no momento atual), sendo a primeira, que se estende dos anos 1980 a 1990, a que se configura pela adoção de políticas avaliativas decorrentes de uma expressiva autonomia relativa dos Estados nacionais. No final dos anos 1990, a forte presença de organizações como a OCDE no campo da educação apontaria a segunda fase, na qual muitos Estados, independentemente das orientações político-ideológicas, participam da "construção de um sistema de indicadores e de avaliação comparada 
internacional em larga escala" (Idem, p. 274), em que se observa certa indiferença em relação às especificidades nacionais.

Afonso (2013) pondera que, se a avaliação comparada (como o Pisa) se espalhou pelo mundo, envolvendo países periféricos e semiperiféricos, isso decorre da busca destes aos objetivos da modernização, do progresso. Dos países capitalistas centrais não é de se esperar que aí estejam por empenho pelo bem comum; antes, legitimam-se, por meio das avaliações comparativas, como os "mais desenvolvidos e competitivos, e supostamente mais cultos e mais educados" (AFONSO, 2013, p. 277), e implicitamente se reforça a crença de que não há alternativa para além do capitalismo. Além disso, reforça-se a lógica da uniformização cultural e científica (orientada por aqueles que, normalmente, direcionam as relações de poder internacionalmente) e, diante da homogeneização, legitimam-se as próprias desigualdades em escala mundial.

Por último, Afonso (2013) discute o que provisoriamente denomina pós Estado avaliador, o que não significa que nessa fase a avaliação perca centralidade, mas, com uma orientação de avaliação estruturada globalmente, sob a ação de forças que operam ao nível supranacional e transnacional, ou seja, que "fugirá cada vez mais do âmbito do Estado nacional (sobretudo em países periféricos e semiperiféricos)" (p. 280). De fato, está em jogo a hegemonia dos estados mais poderosos que, por meio de forte influência dos organismos internacionais e na organização mundial, ditam as regras; consequentemente, há a reprodução do sistema econômico capitalista e a mercadorização da educação, como fonte para acumulação do capital. No entanto, o autor adverte que essas perspectivas não se sucedem linearmente em escala global, mas há diferentes movimentos em consonância.

Da situação radical e pioneira observada especialmente na Inglaterra e nos Estados Unidos em torno dos testes estandardizados como orientadores das políticas educativas, bem como da nova forma de gestão pública que tem configurado relações de quase mercado na educação, tivemos particularidades dessas orientações políticas na realidade de outros países. A incitação à competição entre as escolas, o favorecimento da "livre escolha" dos pais vistos como clientes, o fortalecimento do controle central, o reforço da lógica mercantil, o alargamento de dispositivos de testes estandardizados, a publicação dos resultados dos testes na mídia e a indução de novos valores e demandas no setor público são orientações presentes nas políticas de muitos países; contudo, com grau e intensidade distintos, elas remontam às idiossincrasias de cada Estado.

No Brasil, a força da avaliação em larga escala emerge na década de 1990, mas ganha centralidade a partir da primeira década do século XXI, quando passa a interferir na organização curricular, na estruturação de valores e pressupostos 
do sistema educativo e na rotina dos estabelecimentos de ensino da Educação Básica. Com efeito, são estabelecidas conexões entre financiamento, gestão e processos avaliativos, sendo que a avaliação assume relação formal/legal com a responsabilização e prestação de contas das escolas.

Tais orientações e ações são justificadas no cenário nacional como fundamentos necessários para a garantia da qualidade da educação e passam a ser potencializadas com a criação, em 2007, do Índice de Desenvolvimento da Educação Básica (Ideb), o qual indica uma profunda mudança na avaliação da Educação Básica no país, como é afirmado no Plano de Desenvolvimento da Educação (PDE) (BRASIL, 2007, p.3). O PDE é definido como meio estratégico para a efetivação da qualidade da educação, no qual, segundo o então Presidente da República Luiz Inácio Lula da Silva, estão sintetizados os princípios políticos, os fundamentos teóricos, os métodos e o passo a passo administrativo da gestão do Ministério da Educação, conduzida, naquele momento, por Fernando Haddad. E o "tratamento dado à qualidade" (BRASIL, 2007, p.21) seria possível por meio desse índice, assumido como referência para as principais políticas públicas da Educação Básica emanadas a partir do Plano.

Duas vertentes ancoram a configuração do Ideb: a aferição da qualidade da educação, assentada em uma concepção de avaliação por metas, pela objetividade, em substituição aos critérios subjetivos, além da ideia de transparência e cientificidade das decisões políticas; e o redimensionamento do pacto federativo, ao definir papéis para os entes federados no processo de garantia das metas de melhoria dos índices da educação fixadas entre União, estados, Distrito Federal e municípios, com a paralela contribuição das famílias e comunidades. O Índice é medido a cada dois anos e, segundo seus idealizadores, pretende-se que o país, a partir do alcance das metas municipais e estaduais, tenha média nacional 6 em 2021 - correspondente ao nível médio de desenvolvimento da Educação Básica dos países integrantes da Organização para Cooperação e o Desenvolvimento Econômico (OCDE).

Nesses termos, a defesa do Ideb aparece como condição necessária ao regime de colaboração, uma vez que se justifica pela ampliação da confiabilidade social, pelo direcionamento dos recursos e pela orientação das competências políticas e técnicas. Essa correlação entre qualidade e o Índice demonstra uma relação contraditória, haja vista que, se de um lado é fundamental a avaliação para a transparência das decisões e práticas políticas tanto do sistema quanto das ações das instituições educacionais, por outro é preciso indagar se esse índice é adequado para um diagnóstico fidedigno das reais condições e configurações das instituições escolares no Brasil. Quais os efetivos do índice na relação do Estado com as escolas públicas? 


\section{RESPONSABILIZAÇÃO UNILATERAL E SUAS IMPLICAÇÕES NO TRABALHO DOCENTE}

Muitos foram os avanços no Ideb das 29 escolas pesquisadas; em contrapartida, os professores ainda vivem condições precárias de trabalho. Tal cenário evidencia, de acordo com as narrativas dos profissionais entrevistados, um processo decorrente, sobretudo, de três aspectos por nós assim categorizados: responsabilização unilateral da escola, intensificação do trabalho docente e mecanismos de orientação e preparação mecânica da prática pedagógica para os testes.

Quando solicitamos aos sujeitos que avaliassem a relação do Ideb com o retrato da qualidade da instituição e discorressem sobre os fatores que levavam aos índices obtidos, constatamos, como exposto no Gráfico 1, que para 148 dos 225 entrevistados o resultado dos testes não retrata a qualidade da escola; para 70, os resultados representam a qualidade; e para quatro, retratam em parte. Quanto à justificativa diante dos resultados, evidencia-se que esta é orientada pela responsabilização unilateral, seja perante altos ou baixos índices.

\section{Gráfico 1. Fatores que interferem (positiva ou negativamente) nos testes estandardizados}

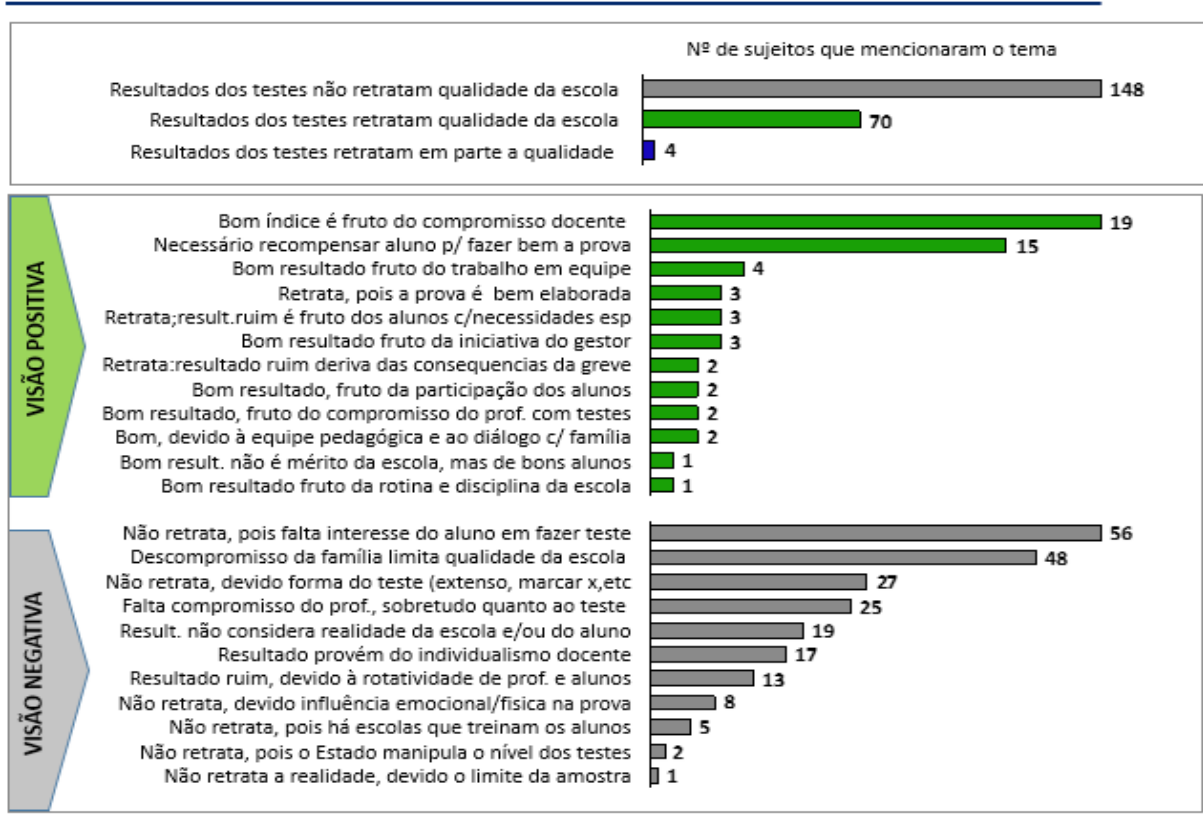

Fonte: Dados da pesquisa, a partir de entrevistas realizadas no primeiro semestre de 2012.

(*) Universo de 225 sujeitos. 
Os fatores que justificam os resultados positivos da escola são: o compromisso docente (19 sujeitos); a prática da escola em recompensar os estudantes para fazer bem a prova (15 sujeitos); o trabalho em equipe (quatro sujeitos); a boa elaboração da prova (três sujeitos); o bom trabalho do gestor (três sujeitos); a participação dos alunos (dois sujeitos); o preparo que o professor faz para os testes (dois sujeitos); o bom trabalho da equipe pedagógica (dois sujeitos); ou devido ao mérito dos alunos (um sujeito) e da rotina e disciplina da escola (um sujeito). Tais dados permitem constatar que, quando os entrevistados assumem que os índices representam a qualidade da escola e os resultados da institução são positivos, isso decorre sobretudo da escola, e não da intervenção do Estado, a fim de colaborar para essas melhoras. Além disso, sustentam um protagonismo normalmente unilateral, ou seja, o sucesso decorre dos atributos individuais de sujeitos ou de uma característica pontual da instituição, e não do coletivo.

Enquanto isso, na percepção daqueles que têm uma visão negativa quanto aos índices como indicativo da qualidade da escola, as justificativas decorrem de fatores como a falta de interesse dos estudantes em fazerem os testes (56 sujeitos); o limitado compromisso da família (48 sujeitos); os problemas do intrumento avaliativo (27 sujeitos); a falta de empenho dos professores com os testes (25 sujeitos); o olhar restrito da avaliação, por não considerar a realidade da escola/ estudantes (19 sujeitos); o individualismo dos docentes que não colaboram para melhorar os resultados (17 sujeitos); a rotatividade de professores e estudantes (13 sujeitos); o impacto emocional na hora do teste (oito sujeitos); o "treino" dos alunos que mascara o resultado (cinco sujeitos); o Estado que manipula o nível do teste (dois sujeitos); e a aferição limitada a alguns anos do Ensino Fundamental (um sujeito). Essas afirmações são emblemáticas de um "olhar míope" que também desconsidera a complexidade da educação e indica "o" responsável.

Ambos os olhares (positivo ou negativo) estão em consonância com a lógica da responsabilização unilateral assumida pelos liberais, defensores da "busca ao culpado". Tanto o sucesso quanto o fracasso são atribuídos ao indivíduo ou a um fator específico, secundarizando a complexidade e a dinâmica dialética de fatores pedagógicos, sociais, econômicos e culturais que interferem no processo educacional. Nessa perspectiva, os testes têm contribuído para reforçar tais princípios no contexto das escolas públicas.

Paralelamente, é nessa mesma lógica que os professores denunciam o sentimento de que são responsabilizados sozinhos pelo desempenho da escola, especialmente porque, sem condições de trabalho apropriadas, tal instituição é obrigada a gerar alternativas para atender às metas externas exigidas pelo Estado, como podemos analisar no Gráfico 2. Para 59 sujeitos, o governo cobra por resultados, mas mantém condições precárias de trabalho; 19 indicam a 
responsabilização unilateral da escola; para outros 19, a responsabilização é mais acentuada sobre os docentes que atuam nos anos e disciplinas avaliadas; seis pessoas afirmam que o Estado deve assumir a sua responsabilidade diante dos resultados dos testes; e três dizem que o Estado tenta transferir sua responsabilidade para as escolas. Como destaca o docente A124, o Estado define metas, exige aprovação dos estudantes e cobra a aprendizagem; contudo, não promove condições dignas de trabalho ao professor, pelo contrário, deixa muitas escolas em situação calamitosa. Tal fórmula não é necessariamente "contraditória", pois está apoiada na lógica neoliberal de responsabilização unilateral e intensificação do trabalho docente.

\section{Gráfico 2. Responsabilização unilateral}

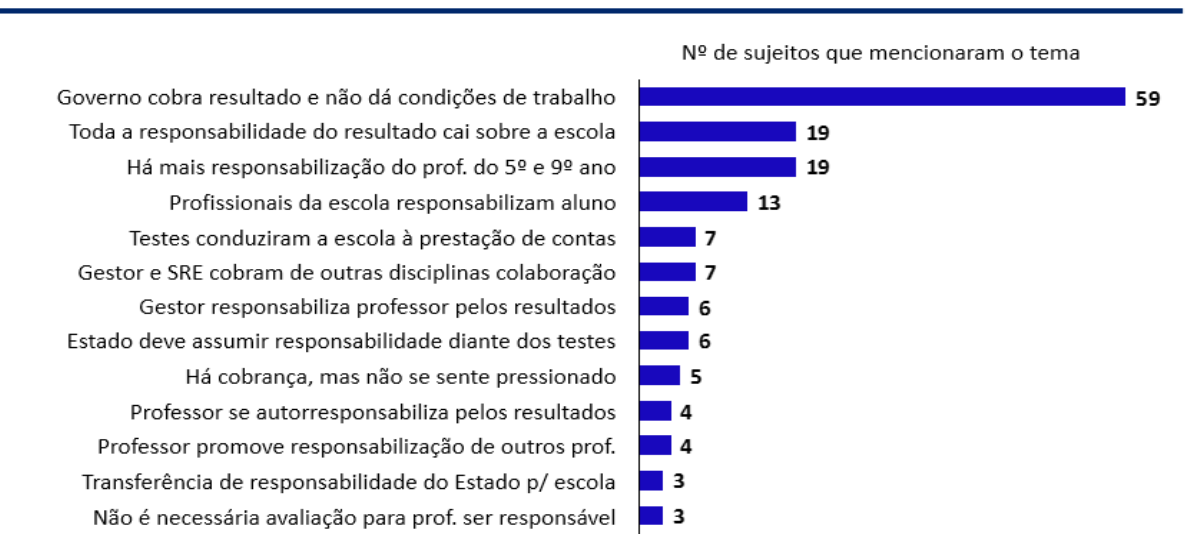

Fonte: Dados da pesquisa, a partir de entrevistas realizadas no segundo semestre de 2012.

(*) Universo de 225 sujeitos.

A responsabilização unilateral da escola provoca o desgaste do professor, como salientam os (as) docentes F35 e E62, visto que, diante de resultados dos estudantes abaixo da meta acordada, os professores são avaliados e questionados em sua prática docente.

O ideal, em termos de avaliação de políticas públicas, é que fossem desenvolvidas ações, projetos voltados para a melhoria da escola, e não é isso que acontece. O que parece é que eles fazem isso com o intuito de colocar a culpa em alguém. (ESCOLA 18, F35, BRASIL, 5 jul. 2012).

[...] As pessoas estão trabalhando extremamente desgastadas, é sobre-humano, é físico. Não é nem tanto o salário, mas o tratamento, a desvalorização profissional no sentido... nesse sentido, o Estado é terrível, é a transferência da responsabilidade pelo fracasso. (ESCOLA 9, E62, BRASIL, 11 jun. 2012). 
No Gráfico 2, há outros movimentos orientados pela lógica da responsabilização unilateral, voltados não para os professores, mas para outros grupos. Para 13 entrevistados, há profissionais que responsabilizam os estudantes pelos resultados; para outros seis, gestores que responsabilizam o professor pelos índices; para quatro, professores que responsabilizam outros professores; e há quatro docentes que se autorresponsabilizam (apenas dois sujeitos fazem uso dos resultados no sentido da autoavaliação). Seja na direção de responsabilização do Estado para a escola; da escola para o Estado; dos professores sobre os estudantes; dos gestores sobre os professores; dos professores sobre os colegas; e dos docentes sobre si mesmos, há, geralmente, um sentido unilateral, e não a responsabilidade como parte da obrigação de um coletivo, cada qual com sua incumbência. Tal visão pouco contribui para a qualidade da educação desenvolvida nas escolas públicas, pois é sustentada por uma lógica da independência dos produtos em relação ao processo numa orientação positivista e tecnicista da avaliação, que, como analisa Dias Sobrinho (1996) tenta abafar a complexidade das situações humanas e a importância das trajetórias e relações vividas: é mais fácil buscar um "culpado" no lugar do "balanço complexo", da "globalidade do objeto como princípio heurístico e a busca em conjunto, através de negociação, das transformações qualitativas desejadas" (p.18).

Como defende Dias Sobrinho (1996), é na avaliação institucional que os professores devem pensar sobre os problemas, as contribuições e as contradições da avaliação em larga escala e criticá-los. No âmbito dessa avaliação, a escola precisa problematizar o significado de qualidade almejada e a concepção que tem orientado o Estado. Essa relação cultural que avalia pontualmente, nega as relações e simplifica a análise da realidade avaliada, que é intensificada pela lógica dos testes que envolvem a avaliação na aparente "clareza" dos números e na objetividade. Nesse sentido, entendemos que os testes têm instigado a cultura da responsabilização unilateral, o individualismo no lugar do coletivo, ou, como destaca o (a) diretor (a) O77, a busca do "culpado" ou do "salvador" no lugar de uma responsabilidade partilhada, uma ideologia ainda marcada pelo nexo meritocrático da avaliação.

Outro aspecto observado nas entrevistas é o reconhecimento de muitos professores acerca da necessidade da avaliação e sua responsabilidade quanto aos resultados. No entanto, citam dificuldades como a falta de jornada integral em uma única instituição (citado por 77 sujeitos); o número limitado de profissionais na escola e, em decorrência, os inúmeros desvios de função (25 sujeitos); a falta de recursos materiais (13 sujeitos); o elevado número de alunos por sala (11 sujeitos); e a falta de formação (nove sujeitos), como destacado no Gráfico 3. 
Gráfico 3. Condições de trabalho docente

Crítica às condições do trabalho

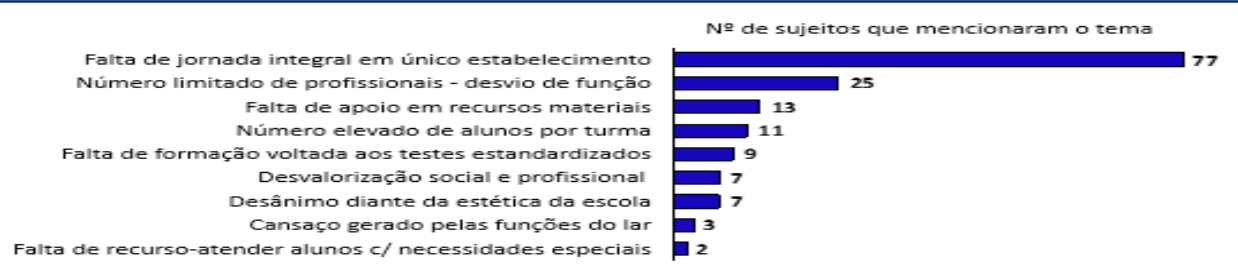

Fonte: Dados da pesquisa, a partir de entrevistas realizadas no primeiro semestre de 2012.

(*) Universo de 225 sujeitos.

Para o (a) professor (a) de Matemática T94, o problema é a forma como a avaliação é usada, pois se exige muito sem que o professor tenha acesso a mais recursos ou apoio. Afirma que a SRE cobra mais qualidade, mas sem gerar mais gastos para o Estado, ou seja, quer, desde que a escola e, sobretudo, o professor o faça. Segundo os docentes A124 e T94, como efeitos temos mais trabalho.

Querem [estado] que saia [estudante aprovado] porque tá gastando muito dinheiro ficando retido, né? E querem que eles aprendam, só que não dão as condições para eles, não perceberam que a sociedade mudou também, que as coisas são mais difíceis, que tá fora dos muros da escola. [...] Só que quem manda é o capital, né? Eles querem que os alunos vão, mas avaliam pra ver se ele aprendeu, aí você acha que em cima de quem que cai? Como que eles querem isso? Porque são duas coisas contraditórias (ESCOLA 23, PROF. HIST. A124, BRASIL, 28 jun. 2012).

[...] eu não sou contra essas avaliações, eu sou contra a forma como tem sido passado isso pra nós, você tá entendendo? Porque é uma coisa que está jogada de cima pra baixo. [...] Chegam pessoas aqui para intervir na escola e que não têm experiência nenhuma de sala de aula, têm experiência só de papel, né? [...]. Vou te falar, veio uma analista da Superintendência e pediu pra assistir minha aula. Ela chegou lá e falou “que não era isso que ela queria ver", e eu: "O que você quer ver?”, "Ah eu quero ver você recortar, você encaixar, você não sei o quê...” [...] Não tem como, você não tem material, você não tem nada. Então vem para te criticar, e não para te ajudar. [...] Eles querem aumento de qualidade, mas sem gerar gastos para o estado, eu acho que é mais ou menos isso. [...] Então, eles querem desde que vocês façam [...] (ESCOLA 15, PROF. MAT. T94, 4 jun. 2012).

A redução de profissionais e a ampliação de funções até então realizadas por outros profissionais (operar fotocopiadora, intervir diante de acidentes com os estudantes, ser psicólogo, professor eventual, ou até mesmo exercer funções de colegas de áreas específicas, como no caso dos docentes de Educação Física, o que, no estado de Minas Gerais, passou a ser atribuição dos professores regentes na última gestão do PSDB no estado) fazem parte do corte de recursos presente 
na lógica do Choque de Gestão ${ }^{2}$ em Minas Gerais, assim como da ideia de um profissional polivalente.

Segundo os professores, a intensificação do trabalho é decorrente do processo de "culpabilização", pois, diante da pressão no sistema educativo e social, os docentes passam a se sentir coagidos. Para o(a) professor(a) regente F189, as avaliações têm contribuído, mas o professor se vê abandonado e sem apoio, e vive a pressão dos testes como uma "arma apontada para a sua cabeça". Quando ele não atende às expectativas, é julgado como o único "errado" e, nessa realidade, se sobrecarrega, como afirma o(a) docente P38, o qual exemplifica que ocupa o horário das aulas de Educação Física, Ensino Religioso e até mesmo o horário de planejamento para trabalhar com estudantes considerados de baixo desempenho nos testes estandardizados.

O governo tem cobrado muito porque a prova [testes estandardizados] exige, fala, mas para nós professores, praticamente não tem feito nada, não dá condições. Precisamos estimular a leitura, mas não tem ninguém na biblioteca, assim como no laboratório de informática. É muita responsabilidade sobre o professor. Eu estou com o projeto de leitura e estou lá dando conta da biblioteca... quando ainda se usa lá o mimeógrafo [...] não é para ficar xerocando, e tem escola que nem tem máquina de xérox. Nossa biblioteca é escura, e os livros não ficam bem organizados pela professora readaptada [...]. Ela tem muitas funções, por exemplo, vai para o bar e a pessoa não é preparada, está lá só porque tem que estar em algum lugar, e não por ter preparo (ESCOLA 18, PROF. PORT. P38, BRASIL, 25 maio 2012).

Contribuem [avaliação em larga escala] muito, é uma mediação do que realmente está acontecendo em tempo real. É um norte, todo trabalho deve ser avaliado. [...] O que eu não concordo é a forma, pois é uma arma apontada para a sua cabeça, e falta apoio, quando falo em professor bem pago, essa questão do salário..., mas não é só isso, essas condições hoje... o professor fica com as mãos amarradas. [...] tem aluno que não respeita, não valoriza o professor, sempre o professor é o errado. Acho que por isso que frustra o professor, essa falta de apoio (ESCOLA 3, PROF. REGENTE F189, BRASIL, 6 jun. 2012).

O efeito mais objetivo da responsabilização é materializado no estado mineiro com a "intervenção pedagógica" da SRE na escola, situação na qual um analista educacional passa a acompanhar a rotina da instituição e a "fiscalizar" o trabalho pedagógico e as estratégias para superar o baixo desempenho nos

2 De acordo com Vilhena e Marini (2011), a expressão "Choque de gestão" deriva do documento elaborado pelo Banco de Desenvolvimento de Minas Gerais (BDMG), que realizou, ao longo de 2002, como o faz a cada 10 anos, um estudo sobre a economia mineira, denominado Minas Século XXI, sendo que nessa edição introduziu um capítulo sobre a administração pública estadual. Nesse documento, destaca-se a necessidade de um "verdadeiro choque de gestão"; assim, tal expressão foi incorporada como ideia-força do programa de governo. 
índices. O receio de muitos professores em ter baixo desempenho está associado ao temor de a escola sofrer "intervenção pedagógica".

Além disso, a pressão exercida sobre essas instituições também ocorre pelo estigma. Na concepção formativa de avaliação, rotular e expor publicamente os problemas da escola não colabora com sua melhora; ao contrário, tende a gerar um clima negativo, pois não se deseja trabalhar ou estudar em uma instituição "taxada como ruim".

\begin{abstract}
Não sei se concordo ou não, acho que é o caminho. Infelizmente não tem como mudar isso. [...] Você vai deixar seus pontos despencarem? Tem que acontecer, concorde ou não. Ou pode ter alguém aqui que não concorde, mas não tem jeito de desviar disso aí. [...] Eu, por incrível que pareça, não sei se é o certo, mas eu concordo. Ajudou porque essa escola aqui estava com baixo desempenho. Então, qual é a proposta? Eu sei que a pressão é muita, não estou dizendo que não, porque você acaba fazendo, né? Mas ninguém quer ter uma escola estratégica, eu tenho certeza, entende? Então, se a gente não quer que as pessoas [analista educacional] estejam aqui dentro, o que é muito complicado, então a gente tenta fazer o que a gente pode, dentro das nossas possibilidades [...] (ESCOLA 24, EEB E139, BRASIL, 28 jun. 2012).

[...] Superintendência, a própria Secretaria de Educação, eles ficam monitorando quase que sempre esses resultados, e o monitoramento faz com que determinadas políticas ajam em determinadas escolas, ainda não abrangem 100\% porque inicialmente a Secretaria está preocupada com as mais, que tenha os piores resultados, que são as chamadas escolas estratégicas. A nossa, nesse decorrer de avaliação, nunca foi, mas eu sinto que quando existem essas escolas estratégicas, existe uma intervenção nessas escolas e há uma cobrança exacerbada em cima do diretor e em cima dos professores, aí esse monitoramento fica diário, ou semanal. Hoje, se você ser taxado de escola estratégica, você é pejorativo no sentido negativo (ESCOLA 22, DIRETOR O156, BRASIL, 12 jun. 2012).
\end{abstract}

Ser escola em intervenção provoca novas demandas de trabalho, como sugere o(a) professor(a) de Português K60, o(a) qual está em uma escola que não vive a ação efetiva da intervenção; contudo, esse receio o faz buscar o atendimento aos testes. Na realidade dos(as) professores(as) A104 e N49, há o impacto objetivo dos testes sobre a docência, pois já estão em "intervenção pedagógica". Podemos entender que a docência nas escolas em intervenção têm consequências distintas das que não têm a presença constante da analista, pois estas vivem, além da pressão de superar os índices, também o olhar presente e vigilante sobre sua prática. Seria então sobre as escolas que tiveram menores índices iniciais e que enfrentaram mais dificuldades para manter ou avançar na nota que há impacto mais direto sobre a autonomia docente. Todavia, nas duas realidades, de forma mais ou menos incisiva, há um sentimento de abalo de suas autonomias, pois o professor exerce a prática pedagógica orientando-a aos testes externos. 
Eu faço o que pedem para fazer, mas falar "foi por culpa minha que baixou o índice, eu não faço isso" ou "Nossa! Foi graças ao meu trabalho que subiu tanto", não faço isso. [...] Mas o problema que a desvalorização profissional não é só graças a isso, mas vamos pensar na avaliação externa friamente. Se por acaso a escola tem um índice baixo no Ideb, a cobrança da Secretaria vai ser maior e eles vão vir em cima de mim mesmo. Eu vou ter que fazer um monte de coisinhas e "coisonas" para tentar sanar uma coisa que eles creem que foi incompetência minha (ESCOLA 9, PROF. PORT. K60, BRASIL, 25 maio 2012).

[...] atividades que você tem que mostrar para as analistas; olham diário, planejamento, confere que conteúdo... se está de acordo com o diário... isso que aborrece, pois temos que prestar contas (ESCOLA 16, PROF. PORT. A104, BRASIL, 17 maio 2012).

Nessa conjuntura, é sobre o professor que incide a responsabilidade de superar problemas, mesmo quando há fatores externos e internos à escola que interferem no processo pedagógico e não são de responsabilidade do docente ou, até mesmo, questões sociais, sobre as quais não há condições de atuar, como apontou anteriormente o docente P38, o que causa uma noção de impotência diante das exigências a ele atribuídas. No bojo da realidade do trabalho precário e das novas demandas dos testes, a intensificação do trabalho acaba por se constituir em alternativa para atender às metas.

\section{CONSIDERAÇÕES FINAIS}

Os testes estandardizados envolvem um cenário complexo, cheio de nuanças que por momentos explicitam contradições, as quais fazem parte de uma realidade dinâmica que não é nem positiva nem negativa no sentido maniqueísta. Em nossa análise, a política de avaliação em larga escala parece-nos passo essencial para a formação de uma responsabilidade coletiva e a prestação de contas à sociedade da educação em todo o país.

Contudo, um primeiro ponto a destacar é que no atual modelo o Estado aparece como aquele que detém poder único para responsabilizar a escola pele seu exercício pedagógico. Segundo, a sociedade civil não orienta propostas próprias de accountability da educação pública e nem é instigada a isso pelo Estado. Terceiro, há a tentativa do Estado de orientar a sociedade a tomar os resultados dos testes para responsabilização das escolas, embora nos dados esse movimento de receptividade da comunidade seja mitigado. Quarto, são poucos os professores nas entrevistas, que cotejam a ideia da escola cobrar do Estado a responsabilidade dele na prestação de contas das políticas por ele emanadas e executadas. Quinto, sendo a accountability importante para o enfrentamento dos mandos e desmandos do Estado e daqueles empregados em função pública, da corrupção e da falta de 
qualidade do trabalho oferecido aos cidadãos, é fundamental a organização da sociedade civil a fim de participar desse processo, mas com um olhar construtivo e sustentado pela responsabilidade coletiva. Por outro lado, em nossa visão, a crítica aos testes estandardizados não pode servir para justificar o recuo do Estado de sua obrigação com as políticas de avaliação em larga escala. O que está em questão é o modelo de avaliação e de accountability.

\section{REFERÊNCIAS}

AFONSO, Almerindo Janela. Mudanças no Estado-avaliador: comparativismo internacional e teoria da modernização revisitada. Revista Brasileira de Educação, v.18, n.53, abr./jun. 2013.

- Políticas educativas e avaliação educacional: para uma análise sociológica da reforma educativa em Portugal (1985-1995). Braga: Universidade do Minho, 1998.

ANTUNES, Ricardo. Os sentidos do trabalho: ensaio sobre a afirmação e a

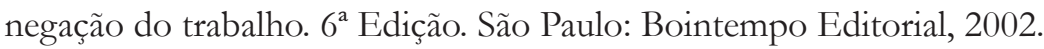

BALL, Stephen. Reforma educacional como barbárie social: economismo e o fim da autenticidade. Práxis Educativa, Ponta Grossa, v.7, n.1, p.33-52, jan./ jun. 2012.

BORON, Atilio. Os "novo Leviatãs" e a pólis democrática: neoliberalismo, decomposição estatal e a decadência da democracia na América Latina. In: SADER, Emir; GENTILI, Pablo. (orgs.) Pós-neoliberalismo II: que Estado para que democracia? $3^{\circ}$ Ed. Petrópolis: Vozes, 2001. p. 07-67.

BRASIL. Ministério da Educação. O Plano de Desenvolvimento da Educação: razões, princípios e programas. Brasília: MEC, 2007.

CHESNAIS, F. A Mundialização do Capital. São Paulo: Xamã, 1995.

DALE, Roger. Globalização e educação: demonstrando a existência de uma "cultura educacional mundial comum" ou localizando uma "agenda globalmente estruturada para a educação"? Educação \& Sociedade, Campinas, v.25, n.87, p.423-460, maio/ago. 2004.

624 - RBPAE - v. 31, n. 3, p. 607 - 625 set./dez. 2015 
DIAS SOBRINHO, José. Avaliação institucional: marcos teóricos e políticos. Avaliação, v.1, n.1, p.15-24, 1996.

HARVEY, David. Neoliberalismo: História e Implicações. São Paulo: Loyola, 2008.

MESZAROS, Istvan. Para Além do Capital: rumo a uma teoria da transição. São Paulo: Boitempo, 2011.

NEAVE, Guy. On the cultivation of quality, efficiency and enterprise: an overview of recent trends in higher education in Western Europe, 1986-1988. European Journal of Education, v.23, n.1/2, 1988.

VILHENA, Renata; MARINI, Caio. Os acordos de resultados de $2^{\text {a }}$ etapa: alinhando a SEPLAG com a segunda geração do Choque de Gestão em Minas Gerais. 2011. Disponível em: http://www.repositorio.fjp.mg.gov.br/consad Acesso em: 7 abr. 2011.

LEONICE MATILDE RICHTER é doutora em Educação, Professora Adjunta do curso de Pedagogia na Faculdade de Ciências Integradas do Pontal (FACIP) da Universidade Federal de Uberlândia (UFU). E-mail: mrleonice@gmail.com

VILMA APARECIDA DE SOUZA é doutora em Educação, Professora Adjunta do curso de Pedagogia na Faculdade de Ciências Integradas do Pontal (FACIP) da Universidade Federal de Uberlândia (UFU). E-mail: vilmasouzza@yahoo.com.br

MARIA VIEIRA SILVA é doutora em Educação, Professora Associada da Faculdade de Educação da Universidade Federal de Uberlândia (UFU). Atualmente é coordenadora do Programa de Pós-Graduação em Educação da UFU. E-mail: mvs@ufu.br

Recebido em novembro de 2015

Aprovado em dezembro de 2015 